\title{
Potential Role of Aminoprocalcitonin in the Pathogenesis of Alzheimer Disease
}

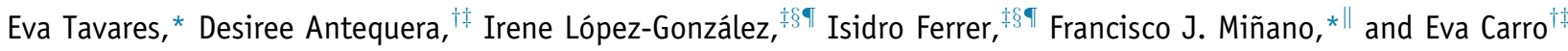

\begin{abstract}
From the Clinical and Experimental Pharmacology Research Unit, $*$ Valme University Hospital, Seville; the Group of Neurodegenerative Diseases, ${ }^{\dagger}$ Instituto de Investigacion Hospital 12 de Octubre (i+12), Madrid; the Centro de Investigación Biomédica en Red de Enfermedades Neurodegenerativas, ${ }^{\ddagger}$

Neurodegenerative Diseases Biomedical Research Center (CIBERNED), Madrid; the Institut de Neuropatologia, ${ }^{\S}$ IDIBELL-Hospital Universitari de Bellvitge, Hospitalet de Llobregat, Hospitalet de Llobregat; the Universitat de Barcelona, ${ }^{\top}$ Hospitalet de Llobregat, Barcelona; and the Department of Pharmacology, Pediatrics and Radiology," Faculty of Medicine, University of Seville, Seville, Spain
\end{abstract}

\author{
Accepted for publication \\ June 9, 2016. \\ Address correspondence to \\ Eva Carro, Ph.D., Neuroscience \\ Group, Instituto de \\ Investigacion Hospital 12 de \\ Octubre (i+12), 28041 \\ Madrid, Spain; or Eva \\ Tavares, Ph.D., Clinical and \\ Experimental Pharmacology \\ Research Unit, Valme Univer- \\ sity Hospital, 41014 Seville, \\ Spain. E-mail: carroeva@h12o \\ es or eva.tavares.exts@ \\ juntadeandalucia.es.
}

\begin{abstract}
Increasing evidence suggests that inflammatory responses cause brain atrophy and play a prominent and early role in the progression of Alzheimer disease. Recent findings show that the neuroendocrine peptide aminoprocalcitonin (NPCT) plays a critical role in the development of systemic inflammatory response; however, the presence, possible function, regulation, and mechanisms by which NPCT may be involved in Alzheimer disease neuropathology remain unknown. We explored the expression of NPCT and its interaction with amyloid- $\beta(A \beta)$, and proinflammatory and neurogenic effects. By using brain samples of Alzheimer disease patients and APP/PS1 transgenic mice, we evaluated the potential role of NPCT on A $\beta$-related pathology. We found that NPCT is expressed in hippocampal and cortical neurons and $A \beta$-induced up-regulation of NPCT expression. Peripherally administered antibodies against NPCT decreased microglial activation, decreased circulating levels of proinflammatory cytokines, and prevented $A \beta$-induced neurotoxicity in experimental models of Alzheimer disease. Remarkably, anti-NPTC therapy resulted in a significant improvement in the behavioral status of APP/PS1 mice. Our results indicate a central role of NPCT in Alzheimer disease pathogenesis and suggest NPCT as a potential biomarker and therapeutic target. (Am J Pathol 2016, 186: 2723-2735; http://dx.doi.org/10.1016/ j.ajpath.2016.06.006)
\end{abstract}

Alzheimer disease (AD) is the most common form of dementia, accounting for approximately $60 \%$ to $90 \%$ of all cases. ${ }^{1} \mathrm{AD}$ is characterized by progressive cognitive and behavioral impairment, and cerebral deposition of senile plaques, extracellular accumulation of $\beta$-amyloid $(A \beta)$ peptide, and neurofibrillary tangles (intracellular accumulation of hyperphosphorylated tau protein) are unique neuropathological hallmarks of the disease., ${ }^{2,3}$ There is a growing body of evidence linking inflammation and the pathogenesis of AD. ${ }^{4,5}$

The brain has been considered to be an immune-privileged organ, isolated from the peripheral immune system. However, recent evidence shows that there is a bidirectional communication between the brain and the peripheral immune system. ${ }^{5}$ Indeed, there has been reported to be an association between systemic inflammation and sepsis, with increased risk of dementia in a case-control study. ${ }^{6-8}$ Although clinical evidence linking the risk of developing $\mathrm{AD}$ and systemic inflammation is still limited and controversial, ${ }^{9}$ some studies have shown that elevated peripheral inflammatory markers are associated with increased risk of dementia, ${ }^{10}$ suggesting a positive correlation between systemic inflammation and neurodegeneration. ${ }^{11}$ In this context, it has been demonstrated that patients who have experienced severe infections show accelerated cognitive decline and this is positively correlated with peripheral levels of tumor necrosis factor- $\alpha$ (TNF- $\alpha){ }^{12}$ Aminoprocalcitonin (NPCT), a 57-amino acid polypeptide derived from the $\mathrm{N}$-terminal half of procalcitonin

Supported by an Instituto de Salud Carlos III (FIS2012/00486) grant, a FEDER grant, Fundación Investigación Médica Mutua Madrileña grant 2010/0004, Fundación Ramón Areces grant CIVP16A1825, and a CIBERNED grant (E.C.). E.T. was supported by the Instituto de Salud Carlos III grant FIS2012/01074, Consejeria de Salud, and Junta de Andalucia grant DP00012/2011 and PI0293/2010.

Disclosures: None declared. 
(PCT), and encoded by the CALCA gene, was initially described as a neuroendocrine peptide with bone cell mitogen activity. ${ }^{13}$ At physiologic homeostasis, NPCT is expressed in key brain regions involved in energy homeostasis, ${ }^{14,15}$ and is detectable at low levels in blood serum in healthy individuals. ${ }^{16}$ However, in sepsis and systemic inflammation, the $C A L C A$ gene is induced by proinflammatory factors, such as IL-1 $\beta$, TNF- $\alpha$, IL-6, and lipopolysaccharides, and cells throughout the body secrete large amounts of PCT and NPCT. ${ }^{17}$ Recent studies suggest that NPCT plays a key role in the pathogenesis of sepsis and may contribute to the deleterious effects of systemic inflammation.

NPCT can elicit a wide range of acute phase responses that occur in the systemic inflammatory response, when administered centrally to rats. ${ }^{14,18-20}$ Elevated plasma levels of NPCT have been associated with severity of sepsis as well as with profound feeding, and neuroendocrine and metabolic effects. ${ }^{21}$ These effects are blocked by central administration of a neutralizing antibody to NPCT. Furthermore, passive or active immunoneutralization of NPCT significantly improves morbidity and survival, and attenuates sickness behavior responses in lethal models of endotoxemia or polymicrobial sepsis induced by cecal ligation and puncture, even when treatment begins after the cytokine response has occurred, ${ }^{17,21}$ suggesting a potential benefit of immunoneutralization of NPCT in the development of sepsis-induced multiorgan dysfunction syndrome. The protective effects of anti-NPCT are associated with down-regulation of proinflammatory cytokine expression and inhibition of inducible transcription factors, such as NF$\kappa \mathrm{B},{ }^{17}$ critical in the transcription of relevant genes and the generation of proinflammatory cytokines involved in inflammatory responses. $^{22}$

On the basis of all these previous findings, and because the presence, possible function, regulation, and mechanisms by which NPCT might be involved in AD neuropathology remain unknown, we assessed the expression of NPCT, explored its interaction with the amyloid- $\beta$ peptide $(A \beta)$, and discussed possible underlying pathway(s) in different in vitro and in vivo experimental models of $\mathrm{AD}$. We demonstrate that $A \beta$ induces up-expression of NPCT and that systemic administration of anti-NPCT attenuates neurodegeneration. Our results indicate a central role of NPCT in the pathogenesis of $\mathrm{AD}$, suggesting it as a potential diagnostic and therapeutic target for $\mathrm{AD}$.

\section{Materials and Methods}

\section{Animal Experiments}

Male double transgenic APP/PS1 mice (3 and 12 months old), B6.Cg-Tg (APPSwe, PSEN1dE9)/J mouse strain, which expresses human APP (Swedish mutation) and presenilin 1 with a deletion in exon 9, were used from our inbred colony (Research Institute Hospital 12 de Octubre). Age-matched mice not expressing the transgene were used as wild-type controls. As a model of toxicity-induced neuronal death, we injected domoic acid $(0.5 \mathrm{mg} / \mathrm{kg}$, i.p.; Tocris Bioscience, Bristol, UK) into adult C57BL/6 male mice $(25 \mathrm{~g})$ to kill hippocampal neurons by excitotoxic damage. ${ }^{23}$ The degree of impairment was evaluated 7 days after domoic acid administration, when the maximum level of deleterious effects of the neurotoxin was reached. ${ }^{23}$

\section{Experimental Design}

Adult male C57BL/6 and APP/PS1 mice were kept under controlled conditions (temperature, $23^{\circ} \mathrm{C} \pm 1{ }^{\circ} \mathrm{C}$ ) on a 12-hour light/dark cycle with food and water ad libitum. Four-monthold male APP/PS1 and domoic-treated mice were chronically treated with anti-NPCT polyclonal neutralizing antibodies to test prevention and amelioration of neurodegeneration. Mice were s.c. implanted with osmotic minipumps releasing 0.11 $\mu \mathrm{L} /$ hour for 28 days (model 1004; Alzet, Palo Alto, CA) prefilled with anti-NPCT $(5 \mu \mathrm{g} / \mu \mathrm{L}$ in phosphate-buffered saline; AbD Serotec, Oxford, UK) or control rabbit nonimmune IgG (Sigma-Aldrich, Madrid, Spain) and primed in sterile phosphate-buffered saline for 2 hours at $37^{\circ} \mathrm{C}$ before implantation. All solutions were passed through $0.22-\mu \mathrm{m}$ pore-size Millipore filters. Implantation was performed on mice under isoflurane anesthesia. The Alzet minipumps delivered anti-NPCT at a dose of $500 \mu \mathrm{g} / \mathrm{kg}$ body weight daily for 28 days. At the end of the treatment, all animals were deeply anesthetized and transcardially perfused with either saline buffer for biochemical analysis or $4 \%$ paraformaldehyde in $0.1 \mathrm{~mol} / \mathrm{L}$ phosphate-buffered saline for immunohistochemical analysis. All experiments were performed following the guidelines for animal care and use promulgated by the Council Directive 2010/63/UE of 22 September 2010.

\section{Human Samples}

Cortical and hippocampal samples from human autopsies were obtained from the Institute of Neuropathology Brain Bank IDIBELL-Hospital Universitari de Bellvitge (Hospitalet de Llobregat, Spain), after the approval of the local ethical committee. The collection of samples conformed to the relevant regulations, ethical considerations, and legislation, as defined by the European Union and Spain. Subjects were selected on the basis of post-mortem diagnosis of $\mathrm{AD}$, according to neurofibrillary pathology and $\beta$-amyloid plaques. Control cases were considered those with no neurological symptoms and with no lesions in the neuropathological examination. The time between death and processing was between 2 and 12 hours.

Demographic characteristics are shown in Table 1.

\section{Cell Cultures}

Primary neuronal cultures from the cerebral cortex and hippocampus were performed as previously described. ${ }^{24}$ Primary cortical and hippocampal neurons were obtained from Wistar 
Table 1 Demographics of Brain Human Samples

\begin{tabular}{|c|c|c|c|c|}
\hline Case no. & Sex & Age (years) & Postmortem* & Diagnosis \\
\hline 1 & $M$ & 76 & 6 & $\mathrm{NL}$ \\
\hline 2 & $M$ & 61 & 4 & $\mathrm{NL}$ \\
\hline 3 & $M$ & 77 & 7 & $\mathrm{NL}$ \\
\hline 4 & $M$ & 63 & 3 & $\mathrm{NL}$ \\
\hline 5 & $M$ & 75 & 6 & $\mathrm{NL}$ \\
\hline 6 & M & 55 & 6 & $\mathrm{NL}$ \\
\hline 7 & $M$ & 64 & 5 & $\mathrm{NL}$ \\
\hline 8 & M & 57 & 10 & $\mathrm{NL}$ \\
\hline 9 & M & 64 & 4 & NL \\
\hline 10 & M & 60 & 9 & NL \\
\hline 11 & M & 85 & 10 & $\mathrm{NL}$ \\
\hline 12 & $\mathrm{~F}$ & 75 & 6 & NL \\
\hline 13 & $\mathrm{~F}$ & 81 & 4 & NL \\
\hline 14 & $\mathrm{~F}$ & 64 & 5 & NL \\
\hline 15 & $\mathrm{~F}$ & 60 & 8 & $\mathrm{NL}$ \\
\hline 16 & $\mathrm{~F}$ & 81 & 5 & $\mathrm{NL}$ \\
\hline 17 & $M$ & 84 & 5 & IV/B \\
\hline 18 & M & 74 & 5 & IV/0 \\
\hline 19 & $M$ & 73 & 3 & IV/0 \\
\hline 20 & M & 75 & 11 & $\mathrm{~V} / \mathrm{B}$ \\
\hline 21 & M & 82 & 4 & $\mathrm{~V} / \mathrm{C}$ \\
\hline 22 & M & 77 & 10 & $\mathrm{~V} / \mathrm{C}$ \\
\hline 23 & M & 61 & 8 & $\mathrm{~V} / \mathrm{C}$ \\
\hline 24 & M & 79 & 7 & $\mathrm{~V} / \mathrm{C}$ \\
\hline 25 & $M$ & 93 & 3 & $\mathrm{~V} / \mathrm{C}$ \\
\hline 26 & $M$ & 63 & 2 & $\mathrm{VI} / \mathrm{C}$ \\
\hline 27 & $\mathrm{~F}$ & 85 & 4 & IV/0 \\
\hline 28 & $\mathrm{~F}$ & 86 & 10 & IV/0 \\
\hline 29 & $\mathrm{~F}$ & 88 & 4 & IV $/ 0$ \\
\hline 30 & $\mathrm{~F}$ & 74 & 4 & IV $/ 0$ \\
\hline 31 & $\mathrm{~F}$ & 74 & 5 & $\mathrm{~V} / \mathrm{C}$ \\
\hline 32 & $\mathrm{~F}$ & 81 & 5 & $\mathrm{~V} / \mathrm{C}$ \\
\hline 33 & $\mathrm{~F}$ & 85 & 5 & $\mathrm{~V} / \mathrm{C}$ \\
\hline 34 & $\mathrm{~F}$ & 86 & 12 & $\mathrm{VI} / \mathrm{C}$ \\
\hline 35 & $\mathrm{~F}$ & 56 & 7 & $\mathrm{VI} / \mathrm{C}$ \\
\hline 36 & $\mathrm{~F}$ & 80 & 5 & $\mathrm{VI} / \mathrm{C}$ \\
\hline 37 & $\mathrm{~F}$ & 63 & 10 & $\mathrm{VI} / \mathrm{C}$ \\
\hline
\end{tabular}

*Postmortem delay in hours.

F, female; M, male; NL, no lesion; IV-VI/0-C, Alzheimer disease-related changes, stages of Braak and Braak.

rat embryos on prenatal day 17 (E17). Cerebral cortex and hippocampus was dissected, incubated for 5 minutes in Neurobasal medium (Gibco, Waltham, MA) at $37^{\circ} \mathrm{C}$ and mechanically dissociated for 5 minutes, and finally centrifuged at $210 \times g$ for 5 minutes at $21^{\circ} \mathrm{C}$. The cells were suspended in Neurobasal medium (Gibco) supplemented with B27 (Gibco), $2 \mathrm{mmol} / \mathrm{L}$ glutamine, $100 \mathrm{U} / \mathrm{mL}$ penicillin, 100 $\mu \mathrm{g} / \mathrm{mL}$ streptomycin, and $0.25 \mathrm{mg} / \mathrm{mL}$ amphotericin B. Cultures were kept at $37^{\circ} \mathrm{C}$ in a humidified atmosphere containing $5 \% \mathrm{CO}_{2}$ for 7 days before experimentation. Then, cultures were incubated in fresh medium with or without $10 \mu \mathrm{mol} / \mathrm{L}$ oligomeric $\mathrm{A} \beta_{42}, 1 \mathrm{mmol} / \mathrm{L}$ pyrrolidine dithiocarbomate (Sigma-Aldrich), and 2.5, 25, or $50 \mu \mathrm{g} / \mathrm{mL}$ anti-NPCT for 48 hours. $A \beta_{42}$ was dissolved in $0.1 \mathrm{~mol} / \mathrm{L}$ acetic acid, and then was diluted in sterile distilled water as previously reported. ${ }^{25}$

\section{Immunoassays}

Western-blotting NPCT assays were performed as described previously. ${ }^{19}$ Proteins were isolated from brain tissue or cell cultures by standard methods. Briefly, brain tissues were homogenized in tris-buffered saline $(50 \mathrm{mmol} / \mathrm{L}$ Tris- $\mathrm{HCl}, \mathrm{pH}$ $7.4,5 \mathrm{mmol} / \mathrm{L}$ EDTA, and $2 \% \mathrm{SDS}$ ) containing a mixture of protease inhibitors. Homogenates were centrifuged, and supernatants were run on $4 \%$ to $20 \%$ SDS-PAGE under reducing conditions. Proteins were transferred to polyvinylidene difluoride membranes (GE Healthcare, Madrid, Spain) and incubated with the specific antibodies. Primary antibodies used were mouse anti-NPCT (1:500; Novus Biologicals, Littleton, CO) and mouse anti- $\beta$-actin (1:10,000; Millipore, Madrid, Spain). Secondary horseradish peroxidase-conjugated goat anti-mouse was used (1:20,000; Bio-Rad Laboratories, Alcobendas, Spain).

$\mathrm{A} \beta$ sandwich enzyme-linked immunosorbent assays (ELISAs) were performed as previously described. ${ }^{26}$ For detection of human $A \beta$, we used a human-specific antibody to $\mathrm{A} \beta\left(6 \mathrm{E} 10\right.$; Sigma) in the first layer and anti-A $\beta_{40}$ or anti$\mathrm{A} \beta_{42}$ (Calbiochem, Madrid, Spain) in the top layer.

Activation of NF- $\kappa \mathrm{B}$ p65 was determined in neuronal cultures by ELISA using a commercially available ELISA kit (Active Motif), as described. ${ }^{27}$

Cell viability within primary neuronal cultures treated with or without $10 \mu \mathrm{mol} / \mathrm{L} \mathrm{A} \beta_{42}$, and $2.5,25$, or $50 \mu \mathrm{g} / \mathrm{mL}$ anti-NPCT, was assessed using Cell Counting Kit-8 (CCK-8 assay; Sigma, St. Louis, MO).

RNA was extracted from mouse cerebral cortex, and TaqMan qRT-PCR assays for each gene were performed as previously described. ${ }^{28}$ Probes included members of proinflammatory and anti-inflammatory cytokines, such as IL-6, members of the TNF- $\alpha$ family, IL-10 and receptors, and transforming growth factor- $\beta$ family.

Plasma samples from mice were centrifuged at $30,000 \times$ $g$ for 20 minutes, and stored at $-80^{\circ} \mathrm{C}$ until cytokine determination. Murine IL- $1 \beta$, IL-6, TNF- $\alpha$, and macrophage inflammatory protein-2 levels in supernatants were measured using a Luminex customized rat 4-plex cytokine assay kit, according to the manufacturer's instructions (Procarta Cytokine Assay Service; Affymetrix, Santa Clara, CA). Data were analyzed using the Luminex Manager software version 2.3. The detection limit was $1.2 \mathrm{pg} / \mathrm{mL}$.

\section{Immunohistochemical Studies}

\section{Animal Tissue}

Fixed brains were cut on a vibratome (Leica Microsystems, Wetzlar, Germany) at $50 \mu \mathrm{m}$, and tissue sections were collected in cold phosphate buffer $0.1 \mathrm{~mol} / \mathrm{L}$, and incubated overnight with primary antibodies at $4{ }^{\circ} \mathrm{C}$. All primary antibodies were diluted in phosphate buffer $0.1 \mathrm{~mol} / \mathrm{L}$ containing $0.5 \%$ bovine serum albumin and $0.5 \%$ Triton X-100. To detect $A \beta$ deposits, brain sections from APP/PS1 mice were preincubated with $88 \%$ formic acid, and immunostained as previously described. ${ }^{26}$ To detect NPCT expression, brain 


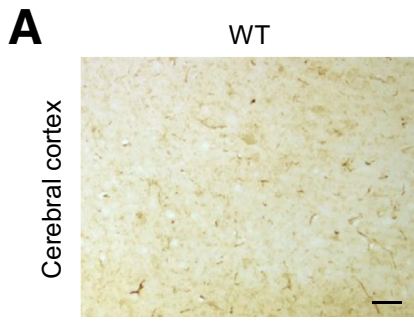

B

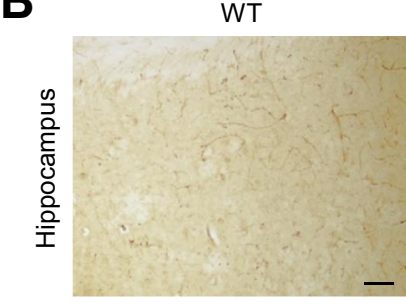

C

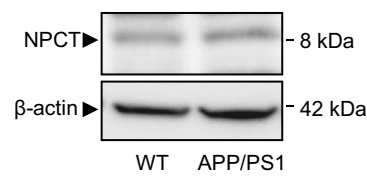

E

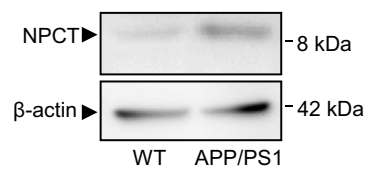

APP/PS1

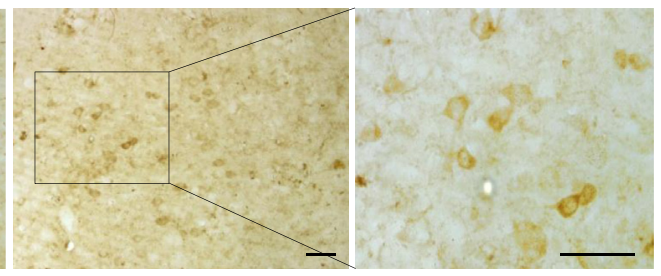

APP/PS1

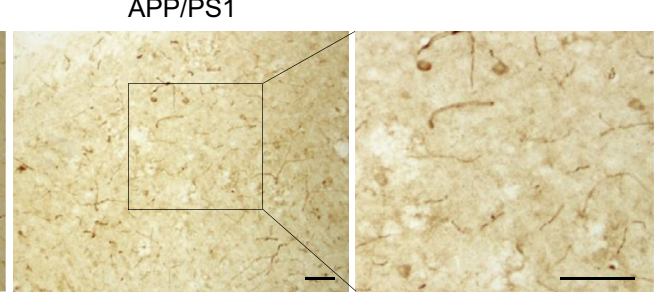

D

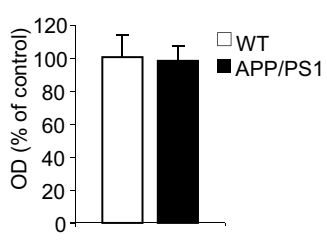

F

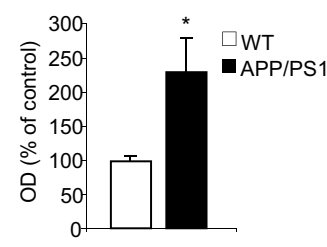

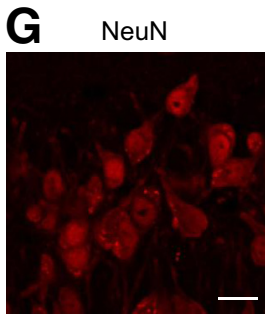

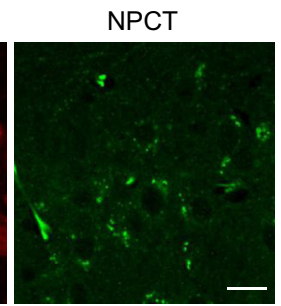

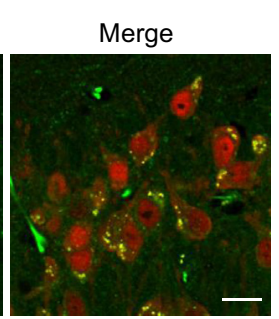

H

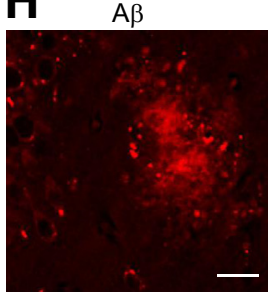

Figure 1 NPCT expression in 12-month-old APP/ PS1 mice. Microphotographs of cerebral cortex (A) and hippocampus (B) showing intense NPCT immunostaining of cells in APP/PS1 mice compared with littermate control mice. C: Representative Western blot of NPCT levels in cortical samples from APP/PS1 and wild-type mice. D: Densitometric quantification of the NPCT protein levels in cortical samples from APP/PS1 mice, and wild-type mice. E: Representative Western blot showing higher NPCT levels in hippocampal samples from APP/PS1 and wild-type mice. F: Densitometric quantification of the NPCT protein levels in hippocampal samples from APP/PS1 mice, and wild-type (WT) mice. G: Confocal images showing that NPCT (red) and NeuN (green) colocalize abundantly in hippocampal neuronal cells. H: Double immunofluorescence assays from cortical sections of APP/PS1 mice showing that NPCT immunostained (green) appear to have an enhanced association with the $A \beta$-immunopositive material (red). Data are expressed as means \pm SEM ( $D$ and $\mathbf{F})$. $n=6(\mathbf{A}-\mathbf{F}$ and $\mathbf{H}) .{ }^{*} P<0.05, t$-test. Scale bars $=$ $20 \mu \mathrm{m}(\mathbf{A}, \mathbf{B}, \mathbf{G}$, and $\mathbf{H})$. sections from APP/PS1 mice were incubated with anti-NPCT antibody, as previously described. ${ }^{19}$ Primary antibodies used were as follows: mouse anti-NPCT (1:300; Novus Biologicals), mouse anti-NeuN (1:1000; Millipore), rabbit anti-A $\beta$ (1:500; Millipore), and rabbit anti-Iba1 (1:500; Wako, Cape Charles, VA). Primary antibody staining was revealed using the avidin-biotin complex method (VECTASTAIN Elite ABC Kit; Vector Laboratories, Burlingame, CA) and diaminobenzidene chromogenic reaction (Vector Laboratories), or fluorescence-conjugated donkey anti-mouse IgG 488 (1:1000; FluoProbes; Interchim, Montluçon France), and Texas Red goat anti-rabbit IgG antibody (1:1000; Jackson Immunoresearch, West Grove, PA).

Iba1 fluorescence intensities were evaluated in the selected brain regions: between bregma 0.7 and $-4.3 \mathrm{~mm}$ (cerebral cortex) and bregma -2.0 and $-4.3 \mathrm{~mm}$ (hippocampus), respectively. All images were taken by the same blinded experimenter (D.A.) using a Zeiss LSM 510 Meta scanning laser confocal microscope (Carl Zeiss Microimaging GmbH, Jena, Germany) with a $40 \times$ objective. Selected $\mathrm{Iba}^{+}$areas were analyzed with ImageJ software version 1.x (NIH, Bethesda, MD), and data were presented as the percentage of fluorescence intensity, and as the number of $\mathrm{Iba}^{+}$proliferative areas.

One additional series was used for Nissl staining with Cresyl Violet (Acros Organics, Morris Plains, NJ). To estimate the number of neurons in the hippocampal hilus, Nissl-positive cells were counted in a one-in-six series of sections under a light microscope (Carl Zeiss Microimaging $\mathrm{GmbH})$ at $\times 40$ magnification, as previously described. ${ }^{29}$

Fluoro-Jade B (Histochem, Jefferson, AR) staining was performed to stain degenerated neurons as described previously. ${ }^{30}$ For stereological analysis, Fluoro-Jade-positive cells were counted in a one-in-six series of sections (300 
mm apart) using a Zeiss LSM 510 Meta scanning laser confocal microscope with a $40 \times$ objective (Leica) throughout the rostral-septal half of the dentate gyrus (from the rostral most extreme of the hippocampus, at bregma $-2.0 \mathrm{~mm}$, to the caudal end, at bregma $-4.3 \mathrm{~mm}$ ). The same areas and number of sections were studied for all of the animals and all of the experimental groups. We considered as Fluoro-Jade ${ }^{+}$those cells completely filled with fluorescent marker. We estimated the cell number of Fluoro-Jade ${ }^{+}$in the dentate gyrus, and expressed it as the number of positive cells per tissue section. Morphometrical analysis was performed using ImageJ.

\section{Cell Culture}

For immunocytochemistry, primary neurons were cultured on poly-L-lysine-coated glass slides, and treated with 10 $\mu \mathrm{mol} / \mathrm{L}$ oligomeric $\mathrm{A} \beta_{42}$ for 48 hours, after which they were fixed in $4 \%$ paraformaldehyde for 1 hour. Then, cells were incubated with a mouse anti-NPCT (1:500; Novus Biologicals), and anti-NeuN (1:1000; Millipore). All primary antibodies were diluted in phosphate buffer 0.1 $\mathrm{mol} / \mathrm{L}$ containing $0.5 \%$ bovine serum albumin and $0.5 \%$ Triton X-100. Secondary antibodies: as above. DAPI $(1: 10,000 ;$ Sigma $)$ was used to stain nuclei.

\section{Behavioral Testing}

After adaptation to human handling, behavioral tests were conducted in APP/PS1 and wild-type non-transgenic mice, treated with anti-NPCT or vehicle pumps, as previously described. ${ }^{31}$ The open field was performed in a box with a $50 \mathrm{~cm} \times 50 \mathrm{~cm}$ surface area, 38-cm-high walls, and a central area with a $25 \mathrm{~cm} \times 25 \mathrm{~cm}$ surface. Ambulatory counts were recorded for a 5-minute period for 3 days. Values were expressed as total number of entrances and total time spent in the central area. Ratio was defined as the time spent in the central area over the total time spent in both central (c) and peripheral (p) areas:

$$
\left[t_{c} /\left(t_{c}+t_{p}\right)\right]
$$

In the elevated plus maze test, the time spent in the different compartments of the maze (open and closed arms), and the number of entrances into the arms, was measured. The open/total arm entrances and duration ratios were then calculated.

\section{Statistical Analysis}

Data are expressed as means \pm SEM. Differences between groups were analyzed with one-way analysis of variance followed by Mann-Whitney post hoc test. Post hoc comparisons between two groups were performed with Student's $t$-test. All calculations were made using SPSS software version 15.0 (SPSS Inc., Chicago, IL). Statistical significance was set at $P<0.05$.

\section{Results}

\section{NPCT Expression in APP/PS1 Mice and AD Patients}

We evaluated NPCT expression in the brains of 3- and 12-month-old APP/PS1 mice using immunohistochemical analysis. We found increased NPCT immunoreactivity both in cortical (Figure 1A) and hippocampal (Figure 1B) cells on sections from 12-month-old APP/PS1 mice compared to age-matched control mice. Further supporting the immunohistochemical data, Western blot analyses were performed. Although NPCT levels were significantly unchanged in cortical samples (Figure 1, C and D), our findings indicated increased NPCT expression in

\section{B}
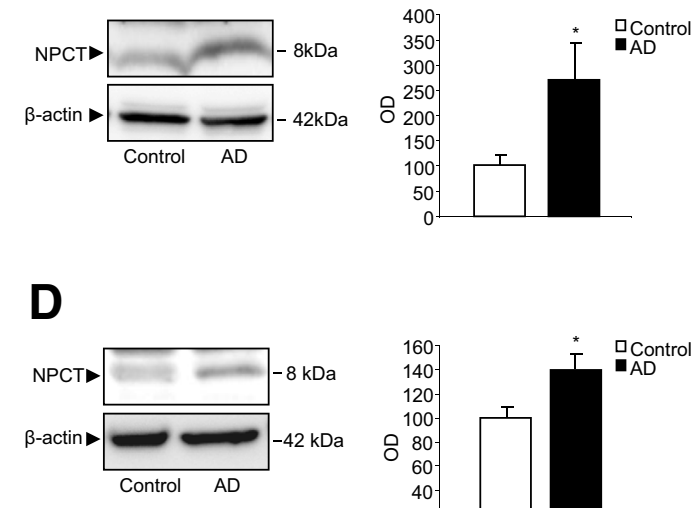

Figure 2 NPCT expression in Alzheimer disease (AD) patients. Microphotographs of cerebral cortex (A) and hippocampus (C) showing intense NPCT immunostaining of cells in AD brain sections compared with control human samples. B: Representative Western blot of NPCT levels in cortical samples from AD and control samples. Densitometric quantification of the NPCT protein levels in cortical samples from AD group, and control human group. D: Representative Western blot of NPCT levels in hippocampal samples from AD samples. Densitometric quantification of the NPCT protein levels in hippocampal samples from AD group, and control human group. Data are expressed as means \pm SEM (B and D). $n=16$ (A-D, AD brain sections); $n=11$ (A-D, control human samples). ${ }^{*} P<0.05$, Student's $t$-test. Scale bars $=20 \mu \mathrm{m}(\mathbf{A}$ and $\mathbf{C})$. OD, percent of control. 
hippocampus from APP/PS1 mice compared to control mice (Figure 1, E and F). We also tested NPCT expression in 3-month-old APP/PS1 mice. Although there was a trend toward increase in the expression of NPCT protein, no significant changes were detected in either hippocampal or cortical samples (data not shown). Doubleimmunofluorescence assays demonstrated that NPCT was mainly expressed in neurons (Figure 1G), as demonstrated using NeuN as a specific neuronal marker. But we also found NPCT immunolabeling in glial cells, including astrocytes (Supplemental Figure S1A), and microglia (Supplemental Figure S1B). Immunoreactivity of NPCT concentrated around the $A \beta^{+}$plaques was evident, using double immunostaining, in the cerebral frontal cortex of APP/PS1 mice (Figure 1H). To exclude cross-reactivity of NPCT with $A \beta$, we replaced the capture antibody of the ELISA system, mouse anti-A $\beta$ clone $6 \mathrm{E} 10$ (Sigma), with an antibody against NPCT, mouse antiNPCT (Novus Biologicals). We did not find any crossreactive signal of NPCT (data not shown).
We next determined NPCT expression in cerebral cortex and hippocampus of human tissue (Figure 2). Levels of NPCT measured by immunohistochemistry and Western blotting were dramatically enhanced in both cortical (Figure 2, A and B) and hippocampal (Figure 2, C and D) samples in $\mathrm{AD}$ patients compared with healthy subjects.

To examine whether A $\beta$ modulates NPCT expression in neuronal cells, primary neuronal cultures were treated with $10 \mu \mathrm{mol} / \mathrm{L}$ oligomeric $\mathrm{A} \beta_{42}$ for 48 hours. We observed a marked increase in NPCT expression induced by $A \beta_{42}$ exposure in cultured neurons (Figure 3A). Quantification of the NPCT immunoreactivity labeling cultured neurons confirmed this increased NPCT expression (Figure 3B). Similar $\mathrm{A} \beta_{42}$-induced overexpression of NPCT was also observed in astrocyte cultures (Supplemental Figure S1C).

As expected, ${ }^{32,33}$ we found that $A \beta_{42}$ activates NF- $\kappa B$. Treatment with oligomeric $10 \mu \mathrm{mol} / \mathrm{L} \mathrm{A} \beta_{42}$ resulted in a significant increase in NF- $\kappa$ B DNA-binding activity in neuronal cultures 48 hours (Figure 3C) after treatment addition. This $\mathrm{A} \beta_{42}$-induced effect on NF- $\kappa \mathrm{B}$ activation
A
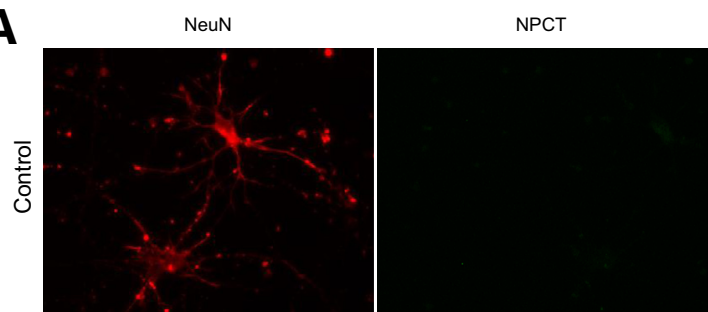

NeuN

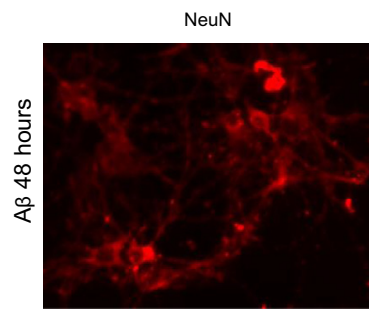

B

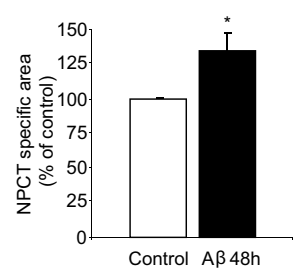

D

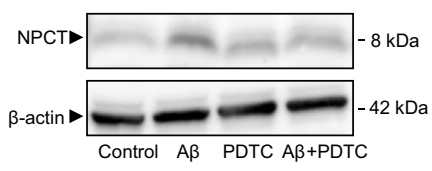

NPCT

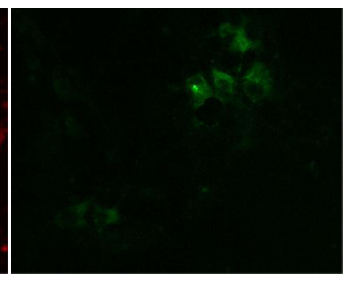

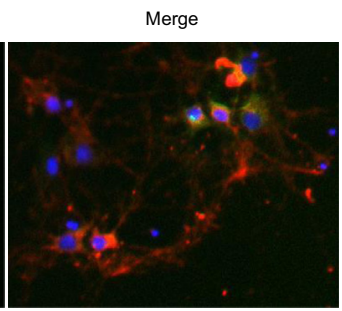

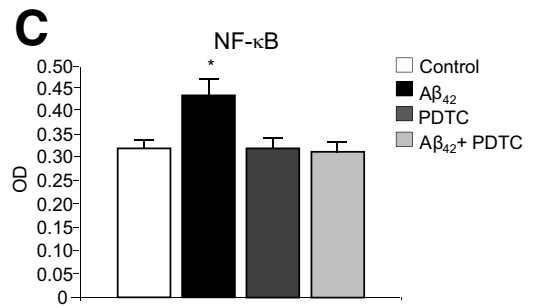

E

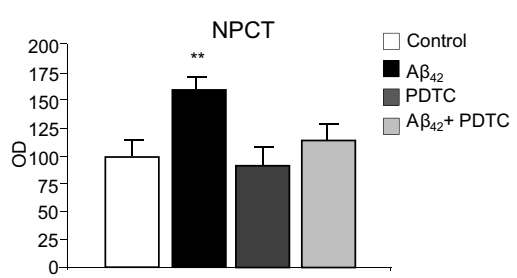

Figure 3 Amyloid $\beta(A \beta)$-induced NPCT expression in neuronal cell cultures. A: Fluorescent photomicrographs of neurons cultured without or with $10 \mu \mathrm{mol} / \mathrm{L}$ $A \beta_{42}$ for 48 hours. Labeling of NeuN (red), NPCT (green), and DAPI-stained nuclei (blue). B: Quantification shows significantly higher NPCT immunoreactivity in neurons incubated with $A \beta_{42}$. Student's $t$-test was used. C: $A \beta_{42}(10 \mu \mathrm{mol} / \mathrm{L})$ treatment increases NF$\kappa B$ DNA-binding activity in neuronal cultures 48 hours, whereas this effect is blocked by adding $1 \mathrm{mmol} / \mathrm{L}$ pyrrolidine dithiocarbomate (PDTC), a selective inhibitor of NF- $\kappa$ B. One-way analysis of variance, followed by Mann-Whitney post hoc test, was used. Representative Western blot (D) and densitometric (E) quantification shows that the inhibition of NF- $\kappa B$ pathway with $1 \mathrm{mmol} / \mathrm{L}$ PDTC clearly abrogates $A \beta_{42^{-}}$ induced NPCT expression. One-way analysis of variance, followed by Mann-Whitney post hoc test, was used. F: Anti-NPCT treatment using several concentrations $(2.5,25$, and $50 \mu \mathrm{g} / \mathrm{mL})$ abrogates $10 \mu \mathrm{mol} / \mathrm{L}$ $\mathrm{A} \beta_{42}$-induced decreased cell viability measured 48 hours after treatment in neuronal cell cultures. Oneway analysis of variance, followed by Mann-Whitney post hoc test, was used. Data are expressed as means \pm SEM (B-F). $n=3$ independent experiments (F). ${ }^{*} P<0.05,{ }^{*} P<0.01$ versus control. Original magnification, $\times 40$. $0 \mathrm{D}$, percent of control.

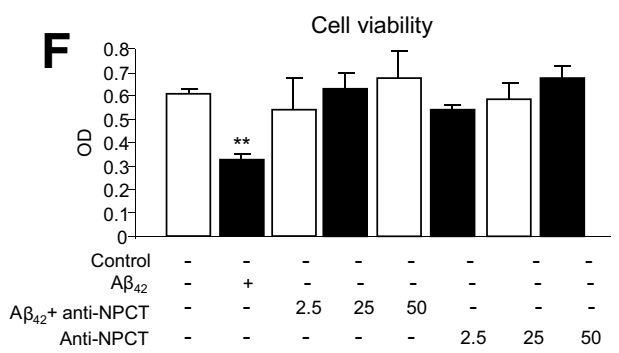


was completely blocked by adding pyrrolidine dithiocarbomate, a selective inhibitor of NF- $\mathrm{BB}$ (Figure 3C). Using pyrrolidine dithiocarbomate, we showed that the inhibition of NF- $\kappa \mathrm{B}$ pathway clearly abrogated the effect of $\mathrm{A} \beta_{42}$ on NPCT expression measured by Western blotting (Figure 3, D and E). Hence, the results obtained herein suggest that $A \beta$ modulates NPCT expression through NF$\kappa \mathrm{B}$ signaling.
Immunoneutralization of NPCT Reduces A $\beta$-Induced Cytotoxicity in Neuronal Cell Cultures

To investigate whether NPCT was able to regulate A $\beta$ induced cytotoxicity, we decided to study the influence of anti-NPCT on the cell death induced by $A \beta_{42}$ exposure. To test this hypothesis, anti-NPCT, and $\mathrm{A} \beta_{42}$ proteins were added to primary neuronal cultures, and CCK- 8 cytotoxicity
A

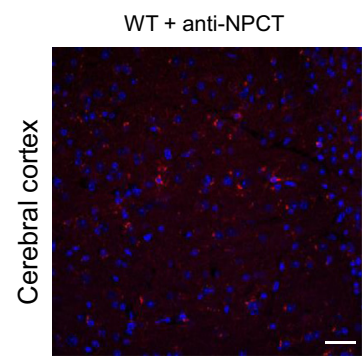

B

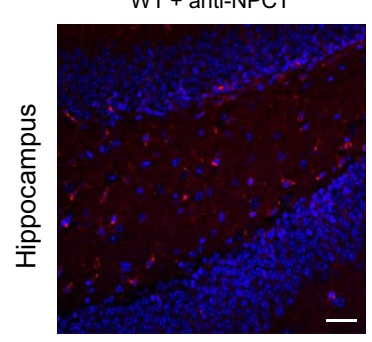

C

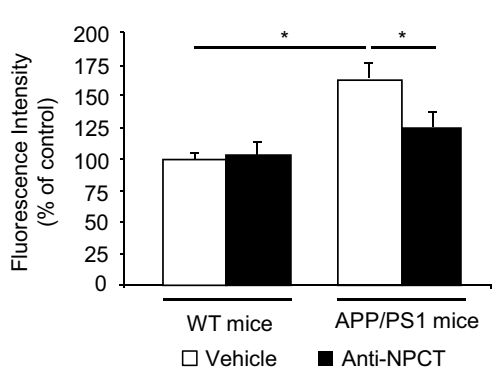

F

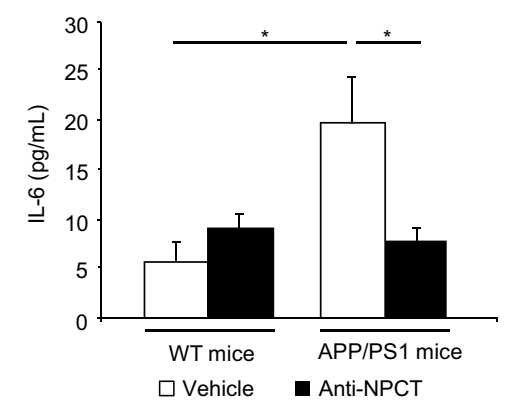

APP/PS1 + vehicle

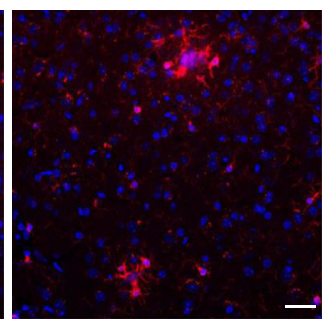

APP/PS1 + vehicle

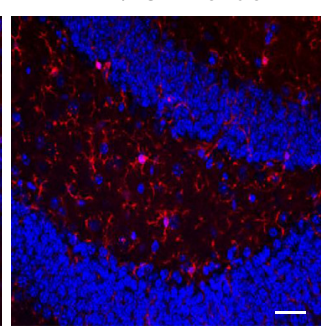

D

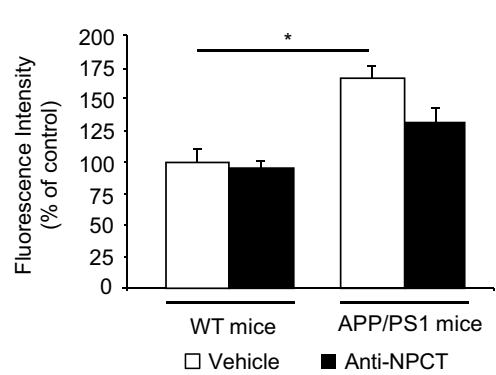

G

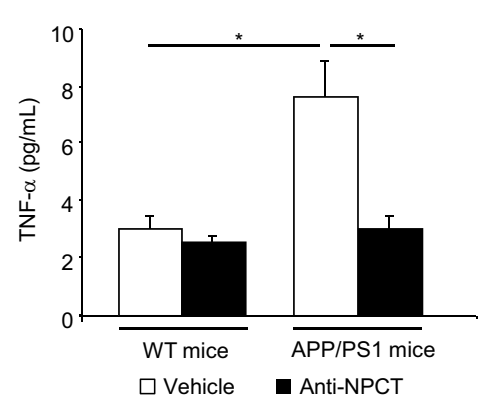

WT + vehicle

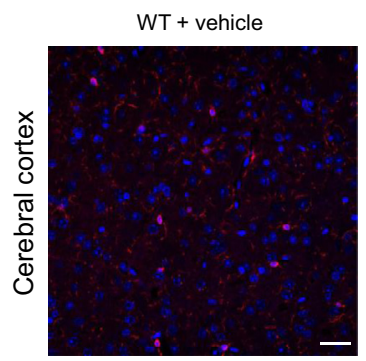

APP/PS1 + anti-NPCT
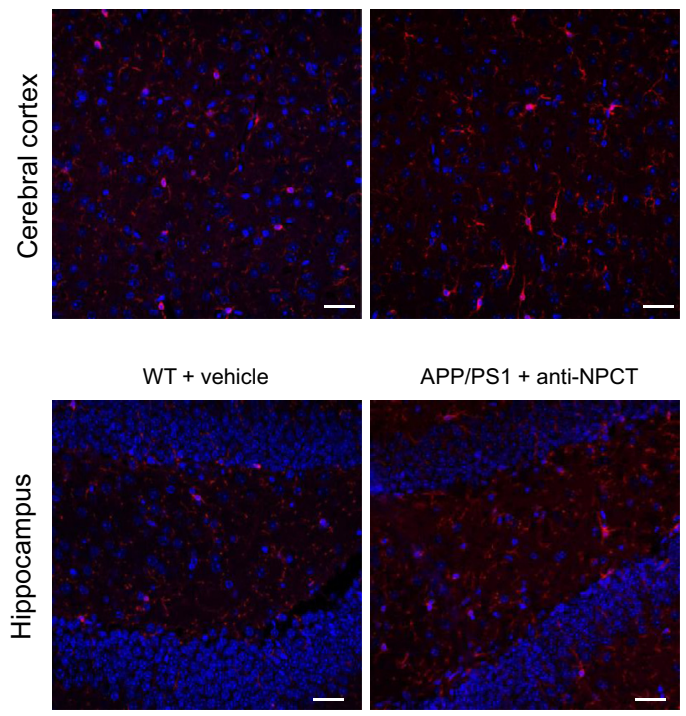

APP/PS1 + anti-NPCT

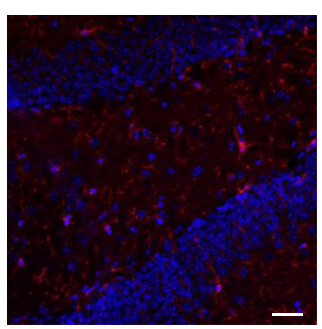

E

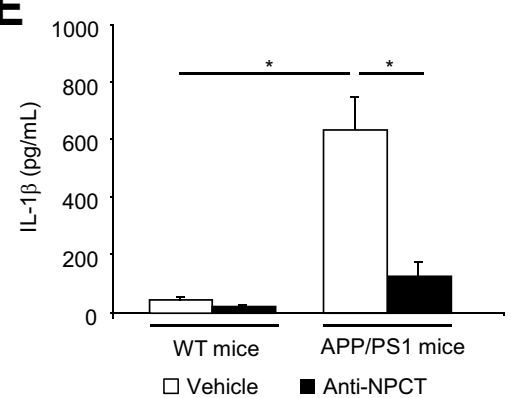

H

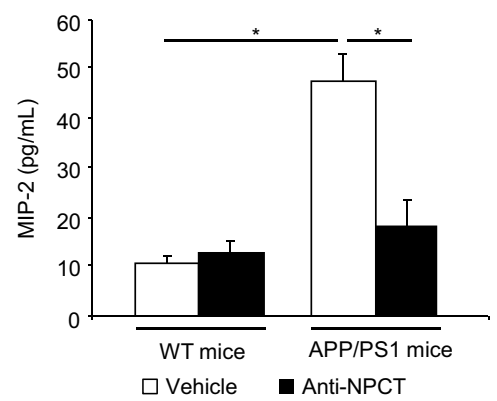

Figure 4 Immunoneutralization of NPCT diminishes microglial activation in 5-month-old APP/PS1 mice. Fluorescent photomicrographs of cortical (A), and hippocampal (B) sections of APP/PS1, and wild-type mice. Labeling of Iba1 (red), and DAPI-stained nuclei (blue). C and D: Quantification shows significantly higher Iba1 immunoreactivity in APP/PS1 mice. Anti-NPCT treatment significantly decreases Iba1 staining in the cerebral cortex (C), but not in hippocampus (D) in APP/PS1 mice. Blood levels of IL-1 $\beta(\mathbf{E})$, IL-6 (F), tumor necrosis factor (TNF)- $\alpha(\mathbf{G})$, and macrophage inflammatory protein (MIP)-2 (H) are higher in APP/PS1mice compared with control mice, whereas these values are significantly reduced 1 month after anti-NPCT treatment. Data are expressed as means \pm SEM (C $-\mathbf{H}) . n=6$ vehicle treated wild-type mice and anti-NPCT treated wild-type mice; $n=7$ vehicle treated APP/PS1 mice; $n=8$ anti-NPCT treated APP/PS1 mice. ${ }^{*} P<0.05$, oneway analysis of variance, followed by Mann-Whitney post hoc test. Scale bars $=20 \mu \mathrm{m}$ (A and B). WT, wild type. 
assay was used for determination of cell viability. As we expected, a significantly reduced cell viability was detected 48 hours after $10 \mu \mathrm{mol} / \mathrm{L} \mathrm{A} \beta_{42}$ treatment, whereas this effect was completely blocked by anti-NPCT treatment using several concentrations $(2.5,25$, and $50 \mu \mathrm{g} / \mathrm{mL}$ ) (Figure $3 \mathrm{~F}$ ).

\section{Immunoneutralization of NPCT Protects against Domoic-Induced Neuronal Loss}

Because neuron loss in APP/PS1 mice is modest, and occurs only in late ages, at approximately 17 months, ${ }^{34}$ we decided to investigate potential neuroprotective effects mediated by NPCT in a good accepted model of neurodegeneration associated with neuronal death. Thus, we tested whether administration of anti-NPCT would also block domoic acid-induced neuronal death. Domoic acid induced marked neuronal damage (Supplemental Figure S2). In domoic acid-treated mice, Nissl-stained neurons of the dentate hilus of the hippocampus were reduced, whereas treatment with anti-NPCT prevented this lesion-induced neuronal death (Supplemental Figure S2A). Stereological quantification revealed that injection of domoic acid in mice resulted in the loss of $>50 \%$ of neurons in hippocampal hilus, compared to control mice $(P<0.05)$ (Supplemental Figure S2B), whereas treatment with anti-NPCT significantly prevented lesion-induced neuronal death (Supplemental Figure S2B).

\section{Immunoneutralization of NPCT Modulates \\ Inflammatory Responses in APP/PS1 Mice}

Activated microglia was visualized via confocal microscopy using brain sections immunostained with the microglial marker Iba1 (Figure 4). The overall Iba1 fluorescence intensities were totally in the cerebral cortex (Figure 4, A and C), or partially decreased in hippocampus (Figure 4, B and D) in 5-month-old APP/PS1 mice treated with anti-NPCT.

Even when microglial activation was enhanced in these APP/PS1 mice, quantitative RT-PCR analysis showed that mRNA expression of selected cytokine-related genes involved in the inflammatory response did not differ between wild-type and APP/PS1 mice at the age of 5 months (at the end of experiment) (Table 2). These findings are in accordance with recent data comparing wild-type and APP/PS1 mice at different ages, and showing increased mRNA expression of the assessed cytokines and mediators in APP/PS1 mice aged 12 months but not at earlier stages when compared with wild-type littermates. ${ }^{28}$ The present findings do not rule out modifications in the expression of mediators at protein level but merely indicate that mRNA cytokine expression in wild-type and APP/PS1 mice is a much regulated mechanism.

Because recent studies have revealed a critical role of NPCT in the regulation of inflammatory responses in peripheral systems, ${ }^{17,21}$ and because $\mathrm{AD}$ is considered as a
Table 2 Cortical mRNA Expression of Selected Cytokine-Related Genes Involved in the Inflammatory Response in WT and APP/PS1 Mice Aged 5 Months

\begin{tabular}{|c|c|c|}
\hline Variable & WT & APP/PS1 \\
\hline \multicolumn{3}{|c|}{ Proinflammatory cytokines } \\
\hline Il-1 $\beta$ & $1.05 \pm 0.15$ & $1.09 \pm 0.12$ \\
\hline \multicolumn{3}{|c|}{ Hematopoietins } \\
\hline Il-6 & $1.01 \pm 0.08$ & $1.14 \pm 0.11$ \\
\hline Il-6st & $1.00 \pm 0.05$ & $0.85 \pm 0.06$ \\
\hline \multicolumn{3}{|l|}{ TNF family } \\
\hline TNF- $\alpha$ & $1.09 \pm 0.25$ & $0.90 \pm 0.21$ \\
\hline TNFrsf1 $\alpha$ & $1.01 \pm 0.05$ & $0.89 \pm 0.10$ \\
\hline \multicolumn{3}{|c|}{ Anti-inflammatory cytokines } \\
\hline \multicolumn{3}{|c|}{ IL-10 family } \\
\hline Il-10ra & $1.00 \pm 0.02$ & $0.90 \pm 0.09$ \\
\hline Il-10rb & $1.01 \pm 0.08$ & $0.96 \pm 0.11$ \\
\hline \multicolumn{3}{|c|}{ TGF- $\beta$ family } \\
\hline TGF- $\beta 1$ & $1.01 \pm 0.06$ & $0.97 \pm 0.14$ \\
\hline TGF- $\beta 2$ & $1.01 \pm 0.08$ & $0.97 \pm 0.12$ \\
\hline
\end{tabular}

Data are represented as the means \pm SEM.

TGF, transforming growth factor; TNF, tumor necrosis factor; WT, wild type.

systemic disorder, we evaluated whether NPCT contributes to $A \beta$ neurotoxicity and $\mathrm{AD}$ pathology by regulating the systemic inflammatory response. Plasma levels of IL-1 $\beta$, IL6 , TNF- $\alpha$, and macrophage inflammatory protein- 2 increased 18.8-, 3.5-, 2.5-, and 4.2-fold, respectively, in APP/PS1 mice compared with wild-type control mice (Figure 4, E-H). However, anti-NPCT treatment decreased the plasma levels of IL- $1 \beta$, IL- 6 , TNF- $\alpha$, and macrophage inflammatory protein- 2 by $81 \%, 64 \%, 60 \%$, and $64 \%$, respectively, in APP/ PS1 mice (Figure 4).

\section{Immunoneutralization of NPCT Diminishes Neurodegeneration in APP/PS1 Mice}

Although Fluoro-Jade B can be used to label activated glial cells that are abundant in the brain of these $\mathrm{AD}$ transgenic mice, it is also known as a high-affinity fluorescent marker for the localization of neuronal degeneration during acute neuronal distress. Widespread FluoroJade $\mathrm{B}$-positive neurons were detected in the cerebral cortex (Figure 5A) and in the hippocampus (Figure 5B) of APP/PS1 mice. Although Fluoro-Jade B staining was unchanged in cerebral cortex of APP/PS1 mice after antiNPCT administration (Figure 5A), we observed that Fluoro-Jade B labeling in the dentate gyrus of APP/PS1 mice decreased significantly after treatment with antiNPCT administration, as compared with vehicle-treated APP/PS1 mice (Figure 5B). Stereological analysis of multiple stained sections revealed that the number of Fluoro-Jade B-positive neurodegenerative neurons was significantly reduced in anti-NPCT-treated APP/PS1 mice compared with vehicle-treated APP/PS1 mice $(P<0.05)$ (Figure 5C). 
A

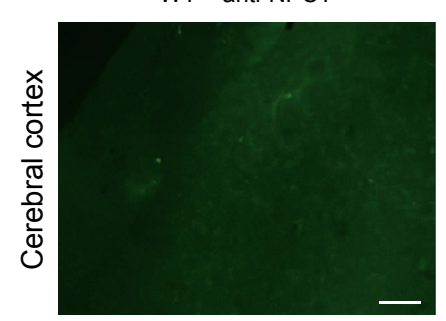

B

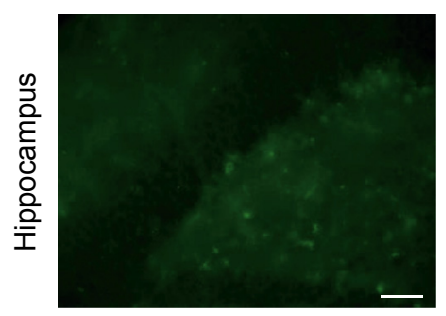

APP/PS1 + vehicle

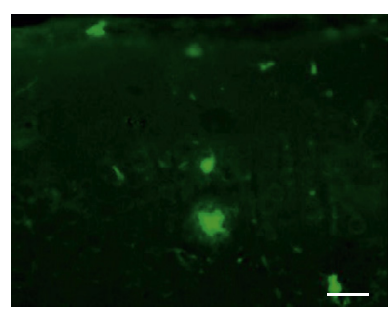

APP/PS1 + vehicle

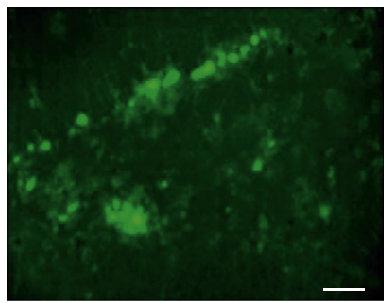

WT + vehicle
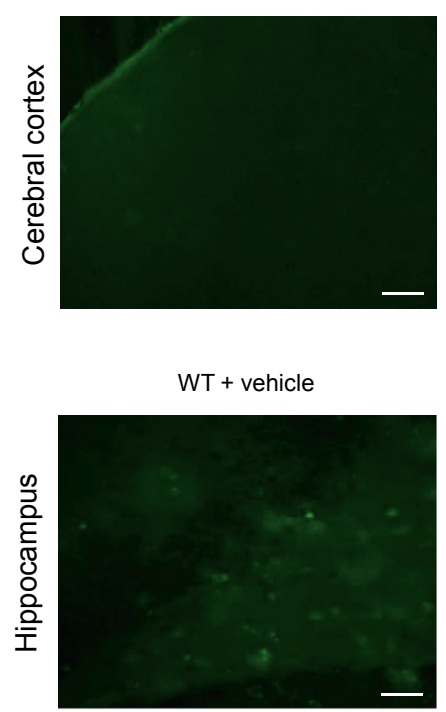

APP/PS1 + anti-NPCT

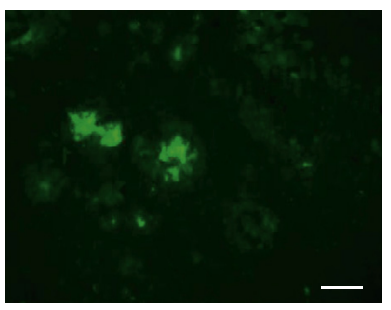

APP/PS1 + anti-NPCT

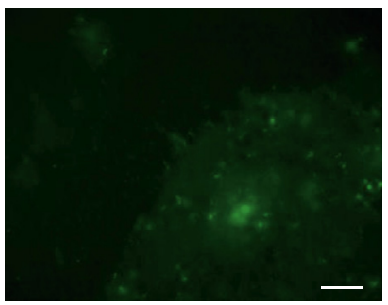

C

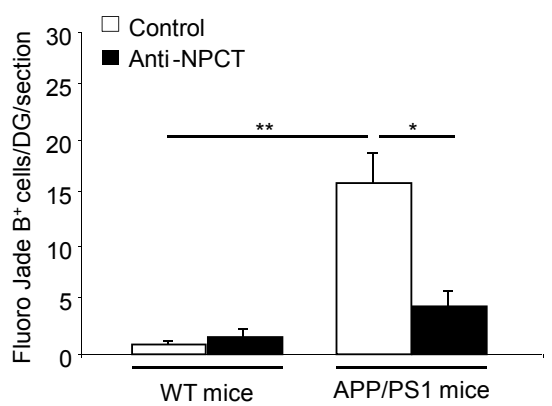

Figure 5 Immunoneutralization of NPCT diminishes neurodegeneration in APP/PS1 mice. Photomicrographs show fluorescent Fluoro-Jade B staining in the cerebral cortex (A) and the hippocampus (B) of APP/PS1 mice, and wild-type mice. C: The histogram shows the number of Fluoro-Jade B-positive cells in APP/PS1, and control mice. Stereological analysis reveals a significant reduction in the number of neurodegenerative cells in the hippocampus after 1 month of anti-NPCT treatment. Data are expressed as means \pm SEM (C). $n=6$ vehicle treated wild-type mice and anti-NPCT treated wild-type mice; $n=7$ vehicle treated APP/PS1 mice; $n=$ 8 anti-NPCT treated APP/PS1 mice. ${ }^{*} P<0.05,{ }^{*} P>0.01$, one-way analysis of variance, followed by Mann-Whitney post hoc test. Scale bars $=20 \mu \mathrm{m}$ (A and B). WT, wild type.

\section{Immunoneutralization of NPCT Alleviates Behavioral Impairment in APP/PS1 Mice}

To determine whether NPCT affected cognitive, exploratory, and anxiety-associated behavior, we examined the performance of APP/PS1 mice treated with anti-NPCT in several tests, as previously described. ${ }^{31}$ In the open field, where emotional states were able to be examined, vehicletreated APP/PS1 mice spent more time in the center area, suggesting disinhibitory tendency, an anxiety-related phenotype, a type of emotional disturbance characteristic of APP/PS1 mice (Figure 6A). However, the behavioral pattern exhibited in anti-NPCT-treated APP/PS1 mice was similar to that observed in wild-type mice (Figure 6A), suggesting that immunoneutralization of NPCT might prevent emotional disturbances. Results in the elevated plus maze, a well-established paradigm to detect both anxiolyticand axiogenic-like behavior, are in agreement with this hypothesis. Anti-NPCT-treated APP/PS1 mice spent significantly less time in the open arms than vehicle-treated APP/PS1 mice, expressed as entry ratio, and similar to what was observed in wild-type mice (Figure 6B).

\section{Discussion}

Our data suggest that brain amyloidosis is linked to increased brain expression of NPCT. To our knowledge, this is the first report of the up-regulation of NPCT in cerebral cortex and hippocampal samples of AD patients and APP/ PS1 mice. High concentrations of NPCT have been associated with inflammation, infection, and sepsis. ${ }^{17,21}$ The inflammatory release of NPCT can be induced either directly, via microbial toxins (eg, endotoxin), or indirectly, via proinflammatory cytokines such as IL-1 $\beta$, IL-6, or TNF$\alpha^{35,36}$ These cytokines play a key role in neuroinflammatory processes, and their overproduction in the central nervous system has been implicated as a key contributor to pathophysiology progression in $\mathrm{AD} .{ }^{37} \mathrm{We}$ herein reported that NPCT expression was increased in 12month-old APP/PS1 mice, whereas it was unchanged in younger mice. Because cytokines are elevated in APP/PS1 mice aged 12 months but not at earlier stages, and $A \beta$ induces up-regulation of IL- $1 \beta$, IL- 6 , and TNF- $\alpha,{ }^{38-40}$ we hypothesized that $\mathrm{A} \beta$ was involved in the enhancement of NPCT expression through stimulation of these 

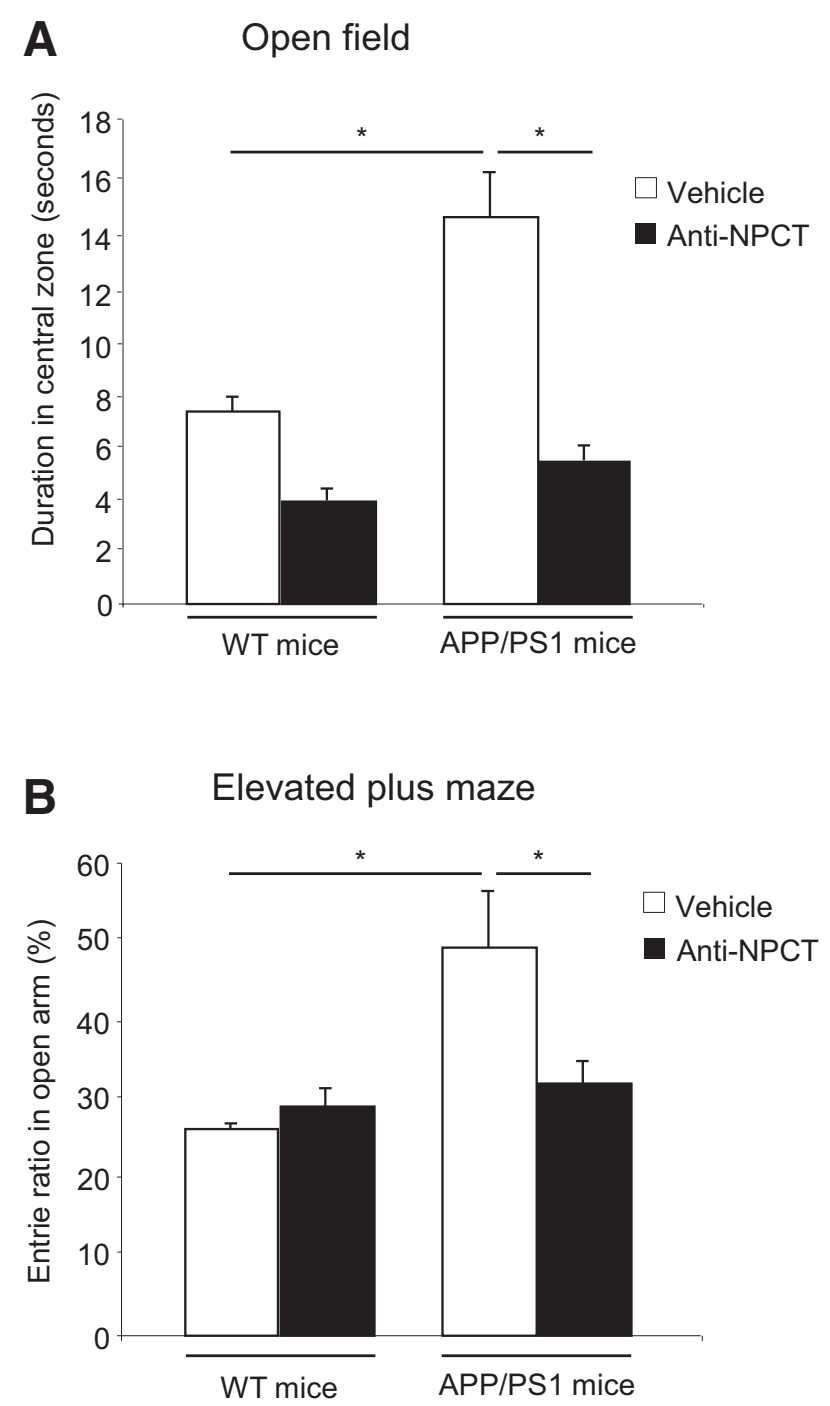

Figure 6 Immunoneutralization of NPCT alleviates behavioral impairment in APP/PS1mice. A: In the open field, APP/PS1 mice spend more time in central zone than wild-type (WT) mice, whereas anti-NPCT-treated APP/ PS1 mice exhibit similar behavior to that observed in control mice groups. B: In the elevated plus maze, anti-NPCT-treated APP/PS1 mice spend significantly less time in the open arms than vehicle-treated APP/PS1 mice, expressed as entry ratio, and similar to what is observed in wild-type mice. Data are expressed as means \pm SEM (A and $\mathbf{B}) . n=7$ (A and $\mathbf{B}$, APP/PS1 mice) $; n=6$ (A, WT and control mice) $; n=8$ (A and $\mathbf{B}$, anti-NPCT-treated APP/PS1 mice). ${ }^{*} P<0.05$, one-way analysis of variance, followed by Mann-Whitney post hoc test.

proinflammatory cytokines. The results of our experiments also suggest that NPCT expression is induced by $A \beta$ via $\mathrm{NF}-\kappa \mathrm{B}$ activation, an effect and signaling pathway similar to that observed in the modulation of proinflammatory cytokines. In agreement with previous data, ${ }^{32,33,41}$ we found that $\mathrm{A} \beta_{42}$ activates NF- $\kappa \mathrm{B}$ pathway modulating downstream cytokine production. Although the precise mechanism involved in A $\beta$-induced NPCT modulation is not completely understood, our findings suggest that selective inhibition of NF- $\kappa$ B pathway suppressed $A \beta_{42}$-induced upregulation of NPCT.
Recent research indicates that NPCT is actively involved in the systemic inflammatory response. It has been shown that NPCT-induced cytokine production is mediated by $\mathrm{NF}-\kappa \mathrm{B}$ activation $^{42}$ and that immunoneutralization of endogenous NPCT with antibodies that are reactive to NPCT significantly improves survival in two different models of lethal sepsis via inhibition of NF- $\kappa \mathrm{B}$ activation and cytokine production. ${ }^{17,21}$ Our results indicate that treatment with anti-NPCT prevents cytokine production and attenuated $\mathrm{A} \beta$-induced cytotoxicity. These findings suggest that the NPCT-mediated neuroprotective effect against AD appears to be associated, at least in part, with blocking NF- $\kappa$ B activation and likely with down-regulating cytokine expression. Although clinical evidence linking the risk of developing $\mathrm{AD}$ and systemic inflammation is still limited and controversial, ${ }^{9}$ some observational studies have shown that elevated concentrations of peripheral inflammatory markers are associated with increased risk of overall dementia, ${ }^{10,11,43}$ suggesting a positive correlation between systemic inflammation and neurodegeneration. Moreover, increased serum proinflammatory cytokines, including IL-6, and TNF- $\alpha$, are associated with $\mathrm{AD}$ and its cognitive deterioration. ${ }^{5}$

Neuroinflammation has been implicated in $A \beta$-induced neuronal death, ${ }^{44,45}$ although its precise role in the development and progression of $\mathrm{AD}$ is not completely clear. $\mathrm{A} \beta$ is a potent and direct neurotoxic agent, and it induces a cascade of cellular mechanisms, including up-regulation of inflammatory cytokines that may play an important role in neuronal death. Multiple preclinical and clinical studies support the causative role of $A \beta$ in the pathogenesis of $\mathrm{AD} .{ }^{46}$ Consequently, $\mathrm{A} \beta$ leads to neurodegeneration and progressive loss of neurons in specific brain regions, some of them involved in cognitive functions, such as hippocampus. In this study, we found neuroprotective effects against $\mathrm{A} \beta$-induced toxicity after immunoneutralization with anti-NPCT. We also used domoic acid-induced excitotoxic damage as a model of experimental neurodegeneration $^{23,29}$ to investigate whether anti-NPCT treatment offers protection against other types of neuronal insults. Excitotoxicity contributes to a variety of disorders in the central nervous system, with the subsequent degeneration of selective populations of neurons in the brain, and associated with cytokines and other inflammatory molecules secreted by activated glia cells. Some studies have shown that peripheral or central administration of domoic acid induces hippocampal-derived seizures and extensive neuronal damage to hippocampal neurons. ${ }^{47,48}$ Our present findings suggest that down-regulating NPCT protects hippocampal neurons against domoic acid-mediated excitotoxicity, probably down-regulating inflammatory cytokine secretion, opening new potential applications in other neurodegenerative disorders.

Noncognitive symptoms, such as agitation, aggression, depression, and psychosis, in addition to progressive cognitive deterioration, are often observed in demented 
patients, including those with AD. These neuropsychological symptoms often exhibit sudden onset and are triggered by an acute change in the patient's physical condition, such as infection, ${ }^{5}$ suggesting that inflammation may play an important role in the pathogenesis underlying these dementia-associated behavioral disturbances. More important, severe neuropsychological symptoms triggered by peripheral infection can develop without signs of sepsis. ${ }^{49}$ On the basis of these reports, it has been hypothesized that systemic infections may contribute to the pathogenesis or pathophysiology of $\mathrm{AD}$, and pathogen-induced chronic infection should be considered a risk factor for sporadic $\mathrm{AD} .{ }^{50} \mathrm{In}$ addition, we agree with the idea that early intervention against infection may delay or even prevent the future development of $\mathrm{AD}$.

In animal models of neurodegeneration, systemic inflammation results in the development of sickness behavior and neuronal cell loss. ${ }^{51}$ In our study, APP/PS1 mice displayed significantly greater exploratory rearing, suggesting anxiety, one of the main characteristic symptoms in AD. However, treatment with anti-NPCT seemed to prevent emotional disturbances in transgenic AD mice. Our study supports the hypothesis that there is a clear cause-andeffect relationship between activated systemic inflammation and the development of neuropsychiatric symptoms in $\mathrm{AD}$, although a mechanistic explanation for the relationship has not been completely formulated (Supplemental Figure S3). The present study has shown increased expression of NPCT in $\mathrm{AD}$ brain of mouse models and patients. In addition, this A $\beta$-induced NPCT stimulation has been described in neuronal cells, and involved the activation of the NF- $\kappa \mathrm{B}$ pathway. Immunoneutralization of NPCT significantly attenuated the $A \beta$-induced cytotoxicity, with a significantly increased survival rate in neuronal cultures, but also an important reduction in hippocampal neurodegeneration, and behavioral impairments in APP/PS1 mice. The beneficial effect of anti-NPCT treatment in these transgenic mice also involved inhibition of peripheral proinflammatory cytokine production. Recently, the significance of systemic inflammation in the etiology of AD has become so prevalent that Krstic and Knuesel coined the term inflammation hypothesis of $\mathrm{AD} .{ }^{52}$ Briefly, they hypothesize that chronic inflammation dysregulates the mechanism for clearing misfolded or damaged neuronal proteins in aging brains that lead to accumulation of APP and synaptic dysfunction. Concomitantly, chronic inflammation also primes microglia to a hyperreactive state that impairs dystrophic neurite clearance, which, in turn, generates a neurotoxic proinflammatory environment that affects neighboring neurons. Elevated levels of inflammatory proteins, notably C-reactive protein and IL- 6 , have been reported in the plasma of AD patients 5 years before the clinical onset of dementia as compared with age-matched individuals. ${ }^{53}$ We support the hypothesis by which early-life or life-long systemic inflammation may trigger microglia priming in the central nervous system. ${ }^{11}$
Later in life, the primed microglia may become hypersensitive, maintain a prolonged activation state, and produce elevated levels of inflammatory mediators that may potentially exacerbate $\mathrm{AD}$ neuropathology and promote neurodegeneration. Thus, in our experimental model using 5-month-old APP/PS1, early up-regulation of proinflammatory cytokines is first detected in blood, when brain cytokine release from microglial reactivity has yet to begin, as proposed by Heneka et al, ${ }^{11}$ suggesting that microglial cells in the brain may be exacerbated by systemic inflammation.

In summary, our results suggest that anti-NPCT immunotherapy ameliorates behavioral deficits, and reduces inflammatory responses and cell death in the brain. Taken together, these findings demonstrate, for the first time, that anti-NPCT may have the potential for attenuating A $\beta$ induced cognitive deficits by reducing inflammatory responses and neurodegeneration, which may add to new evidence for anti-inflammatory properties of anti-NPCT in AD treatment.

\section{Acknowledgments}

We thank Rosario Maldonado for technical assistance.

E.T. and E.C. designed the experiments and wrote the manuscript. D.A. executed biochemical and behavioral experiments. I.L.-G. executed quantitative RT-PCR assays. I.F. and F.J.M. assisted in data analysis and discussion. All authors actively reviewed and edited the manuscript.

\section{Supplemental Data}

Supplemental material for this article can be found at http://dx.doi.org/10.1016/j.ajpath.2016.06.006.

\section{References}

1. Thies W, Bleiler L: Alzheimer's disease facts and figures. Alzheimers Dement 2011, 7:208-244

2. Hardy J, Selkoe DJ: The amyloid hypothesis of Alzheimer's disease: progress and problems on the road to therapeutics. Science 2002, 297 : $353-356$

3. Iqbal K, Grundke-Iqbal I: Discoveries of tau, abnormally hyperphosphorylated tau and others of neurofibrillary degeneration: a personal historical perspective. J Alzheimers Dis 2006, 9:219-242

4. Akiyama H, Barger S, Barnum S, Bradt B, Bauer J, Cole GM, et al: Inflammation and Alzheimer's disease. Neurobiol Aging 2000, 21: $383-421$

5. Holmes C, Butchart J: Systemic inflammation and Alzheimer's disease. Biochem Soc Trans 2011, 39:898-901

6. Dunn N, Mullee M, Perry VH, Holmes C: Association between dementia and infectious disease: evidence from a case-control study. Alzheimer Dis Assoc Disord 2005, 19:91-94

7. Lopez Gonzalez I, Garcia-Esparcia P, Llorens F, Ferrer I: Genetic and transcriptomic profiles of inflammation in neurodegenerative diseases: Alzheimer, Parkinson, Creutzfeldt-Jakob and Tauopathies. Int J Mol Sci 2016, 17:206 
8. Mawanda F, Wallace R: Can infections cause Alzheimer's disease? Epidemiol Rev 2013, 35:161-180

9. Sundelof J, Kilander L, Helmersson J, Larsson A, Ronnemaa E, Degerman-Gunnarsson M, Basun H, Lannfelt L, Basu S: Systemic inflammation and the risk of Alzheimer's disease and dementia: a prospective population-based study. J Alzheimers Dis 2009, 18: 79-87

10. Koyama A, O'Brien J, Weuve J, Blacker D, Metti AL, Yaffe K: The role of peripheral inflammatory markers in dementia and Alzheimer's disease: a meta-analysis. J Gerontol A Biol Sci Med Sci 2013, 68: 433-440

11. Heneka MT, Kummer MP, Latz E: Innate immune activation in neurodegenerative disease. Nat Rev Immunol 2014, 14:463-477

12. Holmes C, Cunningham C, Zotova E, Woolford J, Dean C, Kerr S, Culliford D, Perry VH: Systemic inflammation and disease progression in Alzheimer disease. Neurology 2009, 73:768-774

13. Burns DM, Birnbaum RS, Roos BA: A neuroendocrine peptide derived from the amino-terminal half of rat procalcitonin. Mol Endocrinol 1989, 3:140-147

14. Tavares E, Maldonado R, Miñano FJ: N-procalcitonin: central effects on feeding and energy homeostasis in rats. Endocrinology 2007, 148: 1891-1901

15. Ojeda ML, Ambrosiani J, Maldonado R, Tavares E, Miñano FJ: Identification and localization of procalcitonin-like immunoreactivity in the rat hypothalamus. Neurosci Lett 2006, 408:40-45

16. Tavares E, Maldonado R, Ojeda ML, Miñano FJ: Circulating inflammatory mediators during start of fever in differential diagnosis of gram-negative and gram-positive infections in leukopenic rats. Clin Diagn Lab Immunol 2005, 12:1085-1093

17. Tavares E, Maldonado R, Miñano FJ: Immunoneutralization of endogenous aminoprocalcitonin attenuates sepsis-induced acute lung injury and mortality in rats. Am J Pathol 2014, 184:3069-3083

18. Tavares E, Maldonado R, Miñano FJ: Aminoprocalcitonin-mediated suppression of feeding involves the hypothalamic melanocortin system. Am J Physiol Endocrinol Metab 2013, 304:E1251-E1262

19. Tavares E, Maldonado R, Garcia-Martinez A, Miñano FJ: Central administration of aminoprocalcitonin inhibits food intake and stimulates the hypothalamic-pituitary-adrenal axis in rats via the corticotrophin-releasing factor system. J Neuroendocrinol 2012, 24: $1040-1054$

20. Tavares E, Miñano FJ: Procalcitonin N-terminal peptide causes catabolic effects via the hypothalamus and prostaglandin-dependent pathways. Neuroendocrinology 2008, 88:316-326

21. Tavares E, Miñano FJ: Immunoneutralization of the aminoprocalcitonin peptide of procalcitonin protects rats from lethal endotoxaemia: neuroendocrine and systemic studies. Clin Sci (Lond) 2010, 119:519-534

22. Ghosh S, May MJ, Kopp EB: NF-kappa B and Rel proteins: evolutionarily conserved mediators of immune responses. Annu Rev Immunol 1998, 16:225-260

23. Carro E, Trejo JL, Busiguina S, Torres-Aleman I: Circulating insulin-like growth factor I mediates the protective effects of physical exercise against brain insults of different etiology and anatomy. J Neurosci 2001, 21:5678-5684

24. Alvira-Botero X, Perez-Gonzalez R, Spuch C, Vargas T, Antequera D, Garzon M, Bermejo-Pareja F, Carro E: Megalin interacts with APP and the intracellular adapter protein FE65 in neurons. Mol Cell Neurosci 2010, 45:306-315

25. Dietrich MO, Spuch C, Antequera D, Rodal I, de Yebenes JG, Molina JA, Bermejo F, Carro E: Megalin mediates the transport of leptin across the blood-CSF barrier. Neurobiol Aging 2008, 29: 902-912

26. Carro E, Trejo JL, Gomez-Isla T, LeRoith D, Torres-Aleman I: Serum insulin-like growth factor I regulates brain amyloid-beta levels. Nat Med 2002, 8:1390-1397

27. Crisostomo PR, Wang Y, Markel TA, Wang M, Lahm T, Meldrum DR: Human mesenchymal stem cells stimulated by
TNF-alpha, LPS, or hypoxia produce growth factors by an NF kappa B- but not JNK-dependent mechanism. Am J Physiol Cell Physiol 2008, 294:C675-C682

28. Lopez-Gonzalez I, Schluter A, Aso E, Garcia-Esparcia P, Ansoleaga B, LLorens F, Carmona M, Moreno J, Fuso A, PorteroOtin M, Pamplona R, Pujol A, Ferrer I: Neuroinflammatory signals in Alzheimer disease and APP/PS1 transgenic mice: correlations with plaques, tangles, and oligomeric species. J Neuropathol Exp Neurol 2015, 74:319-344

29. Antequera D, Bolos M, Spuch C, Pascual C, Ferrer I, FernandezBachiller MI, Rodriguez-Franco MI, Carro E: Effects of a tacrine-8hydroxyquinoline hybrid (IQM-622) on Abeta accumulation and cell death: involvement in hippocampal neuronal loss in Alzheimer's disease. Neurobiol Dis 2013, 46:682-691

30. Perez-Gonzalez R, Antequera D, Vargas T, Spuch C, Bolos M, Carro E: Leptin induces proliferation of neuronal progenitors and neuroprotection in a mouse model of Alzheimer's disease. J Alzheimers Dis 2011, 24(Suppl 2):17-25

31. Spuch C, Antequera D, Portero A, Orive G, Hernandez RM, Molina JA, Bermejo-Pareja F, Pedraz JL, Carro E: The effect of encapsulated VEGF-secreting cells on brain amyloid load and behavioral impairment in a mouse model of Alzheimer's disease. Biomaterials 2010, 31:5608-5618

32. Kuner P, Schubenel R, Hertel C: Beta-amyloid binds to p57NTR and activates NFkappaB in human neuroblastoma cells. J Neurosci Res 1998, 54:798-804

33. Delgado M, Varela N, Gonzalez-Rey E: Vasoactive intestinal peptide protects against beta-amyloid-induced neurodegeneration by inhibiting microglia activation at multiple levels. Glia 2008, 56: $1091-1103$

34. Rupp NJ, Wegenast-Braun BM, Radde R, Calhoun ME, Jucker M: Early onset amyloid lesions lead to severe neuritic abnormalities and local, but not global neuron loss in APPPS1 transgenic mice. Neurobiol Aging 2011, 32:2324.e1-2324.e6

35. Oberhoffer M, Stonans I, Russwurm S, Stonane E, Vogelsang H, Junker U, Jager L, Reinhart K: Procalcitonin expression in human peripheral blood mononuclear cells and its modulation by lipopolysaccharides and sepsis-related cytokines in vitro. J Lab Clin Med 1999, 134:49-55

36. Linscheid P, Seboek D, Schaer DJ, Zulewski H, Keller U, Muller B: Expression and secretion of procalcitonin and calcitonin gene-related peptide by adherent monocytes and by macrophage-activated adipocytes. Crit Care Med 2004, 32:1715-1721

37. Bachstetter AD, Norris CM, Sompol P, Wilcock DM, Goulding D, Neltner JH, St Clair D, Watterson DM, Van Eldik LJ: Early stage drug treatment that normalizes proinflammatory cytokine production attenuates synaptic dysfunction in a mouse model that exhibits agedependent progression of Alzheimer's disease-related pathology. J Neurosci 2012, 32:10201-10210

38. McGeer PL, McGeer EG: NSAIDs and Alzheimer disease: epidemiological, animal model and clinical studies. Neurobiol Aging 2007, 28:639-647

39. McGeer PL, Rogers J, McGeer EG: Inflammation, anti-inflammatory agents and Alzheimer disease: the last 12 years. J Alzheimers Dis 2006, 9:271-276

40. Jin JJ, Kim HD, Maxwell JA, Li L, Fukuchi K: Toll-like receptor 4dependent upregulation of cytokines in a transgenic mouse model of Alzheimer's disease. J Neuroinflammation 2008, 5:23-33

41. Couch Y, Alvarez-Erviti L, Sibson NR, Wood MJ, Anthony DC: The acute inflammatory response to intranigral alpha-synuclein differs significantly from intranigral lipopolysaccharide and is exacerbated by peripheral inflammation. J Neuroinflammation 2011, 8:166-180

42. Murakami K, Suzuki C, Fujii A, Kobayashi F, Nakano A, Kamizono A: Intravenous immunoglobulin preparation prevents the production of pro-inflammatory cytokines by modulating NFkappaB and MAPKs pathways in the human monocytic THP-1 cells stimulated with procalcitonin. Inflamm Res 2014, 63:711-718 
43. Takeda S, Sato N, Morishita R: Systemic inflammation, blood-brain barrier vulnerability and cognitive/non-cognitive symptoms in Alzheimer disease: relevance to pathogenesis and therapy. Front Aging Neurosci 2014, 6:171

44. Bornemann KD, Wiederhold KH, Pauli C, Ermini F, Stalder M, Schnell L, Sommer B, Jucker M, Staufenbiel M: Abeta-induced inflammatory processes in microglia cells of APP23 transgenic mice. Am J Pathol 2001, 158:63-73

45. Matsuoka Y, Picciano M, Malester B, LaFrancois J, Zehr C, Daeschner JM, Olschowka JA, Fonseca MI, O'Banion MK, Tenner AJ, Lemere CA, Duff K: Inflammatory responses to amyloidosis in a transgenic mouse model of Alzheimer's disease. Am J Pathol 2001, 158:1345-1354

46. Selkoe DJ, Schenk D: Alzheimer's disease: molecular understanding predicts amyloid-based therapeutics. Annu Rev Pharmacol Toxicol 2003, 43:545-584

47. Ben-Ari Y, Cossart R: Kainate, a double agent that generates seizures: two decades of progress. Trends Neurosci 2000, 23:580-587
48. Ananth C, Sopalakrishnakone P, Kaur C: Protective role of melatonin in domoic acid-induced neuronal damage in the hippocampus of adult rats. Hippocampus 2003, 13:375-387

49. Ebersoldt M, Sharshar T, Annane D: Sepsis-associated delirium. Intensive Care Med 2007, 33:941-950

50. Honjo K, van Reekum R, Verhoeff NP: Alzheimer's disease and infection: do infectious agents contribute to progression of Alzheimer's disease? Alzheimers Dement 2009, 5:348-360

51. Cunningham O, Campion S, Perry VH, Murray C, Sidenius N, Docagne F, Cunningham C: Microglia and the urokinase plasminogen activator receptor/uPA system in innate brain inflammation. Glia 2009, 57:1802-1814

52. Krstic D, Knuesel I: Deciphering the mechanism underlying lateonset Alzheimer disease. Nat Rev Neurol 2013, 9:25-34

53. Engelhart MJ, Geerlings MI, Meijer J, Kiliaan A, Ruitenberg A, van Swieten JC, Stijnen T, Hofman A, Witteman JC, Breteler MM: Inflammatory proteins in plasma and the risk of dementia: the Rotterdam study. Arch Neurol 2004, 61:668-672 